\title{
Effect of a Mental Stimulation Program of Computer and Internet Learning on Cognitive Functions and Wellbeing in Older Community-Dwelling Mexicans
}

\author{
José Miguel Sánchez-Nieto ${ }^{1}$, María de la Luz Martínez-Maldonado ${ }^{2}$, \\ María Montero-López Lena ${ }^{3}$ and Víctor Manuel Mendoza-Núñez ${ }^{2, *}$ \\ 1 Doctoral Program in Psychology, National Autonomous University of Mexico, Mexico 04510, Mexico \\ 2 Research Unit on Gerontology, FES Zaragoza, National Autonomou, University of Mexico, \\ Mexico 04510, Mexico \\ 3 Faculty of Psychology, National Autonomous University of Mexico (UNAM), Mexico 04510, Mexico \\ * Correspondence: mendovic@unam.mx; Tel.: +52-55-5623-0721
}

Received: 13 May 2019; Accepted: 24 June 2019; Published: 27 June 2019

\begin{abstract}
Background: It has been reported that Mental Stimulation (MS) has a positive effect on cognitive functions and wellbeing. In this sense, different training activities have been proposed for MS such as theater, learning a new language, playing a musical instrument and computing, however, there are few studies on older adults in Latin American countries. For this reason, the purpose of the present study was to determine the effect of a mental stimulation program (MSP) of computer and Internet learning on cognitive functions and wellbeing in older community-dwelling Mexicans. Method: A quasi-experimental pilot study was carried out in a convenience sample of 27 adults aged 60 to 69 years, without knowledge of the use of computers and Internet, without chronic non-communicable diseases, depression or cognitive impairment. Two groups were formed: (i) experimental (EG), $n=16$ and (ii) control (CG), $n=11$. The EG participated in an MSP in which 20 theoretical/practical sessions of two hours each were given, two times a week, on computer and Internet. The CG did not participate in any scheduled activity. All participants were measured before and after the intervention program in processing speed (PS), cognitive inhibition (CI), working and episodicmemory (WM and EM), visuospatial processing (VP), life satisfaction (LS) and positive and negative emotions (PE and NE). Results: After participation in the MSP, the EG showed significantly higher scores on the EM and VP tests compared to the CG $(p<0.05)$. Conclusions: Our findings suggest that an MSP of computer and Internet learning improves episodicmemory and visuospatial processing in older community-dwelling Mexicans.
\end{abstract}

Keywords: mental stimulation; computer and internet; learning; cognitive functions; older communitydwelling Mexicans

\section{Introduction}

Mental stimulation (MS) refers to interventions that promote participation in intellectually stimulating activities to maintain or improve the cognitive functions of older adults. In this sense, it has been shown that different training activities of MS such as theater, playing a musical instrument, learning a new language or competence such as computation and Internet, can improve or maintain cognitive functions [1]. It has also been proposed that MS could improve wellbeing [2,3].

For MS to have an effect on cognitive functions, we must consider that the task has to encourage the use of cognitive processes, self-initiated processing, new learning and adjust the difficulty of the task for the person to perform a high cognitive effort, without exceeding its limits [3,4]. Also, the increase in wellbeing 
can be facilitated by the incorporation of positive comments focused on the task, and an environment that promotes autonomy, competence and relationship [5].

In the present study, computer and Internet learning was chosen as an activity for the mental stimulation program (MSP), considering that a high percentage of the Mexican elderly population does not have the basic knowledge about the use of computers and the Internet. Hence, this activity fulfills the requirement of being a new knowledge, it also requires self-initiated processing and may have an increasing level of difficulty, as well as having been associated whith greater wellbeing [6]. It has also been shown that the use of the computer is positively related to performance in cognitive tests and a lower probability of developing mild cognitive impairment $[7,8]$.

Knowledge about the effect of computing on the cognitive functions of older adults is not entirely consistent. Slegers et al. (2009) found that the use of computation does not have an effect on cognitive functions and wellbeing [9]. However, Klusmannet al. (2010) found that learning the use of the computer and the Internet has a positive effect on long-term memory [10]. Also, Chan et al. (2016) observed that teaching the use of tablets, speed of processing and episodic memory of the participants improve, but not working memory and visuospatial processing [11]. In adittion, Vaportzis et al. (2016) conducted a similar study, finding a positive effect on processing speed, but not in working memory [12]. Therefore, considering the findings of the quoted studies, we infer that MSP through computer and Internet learning will maintain or improve cognitive functions and wellbeing in older adults.

In this context, the purpose of the present study is to determine the effect of an MSP of computer and Internet learning on cognitive functions and wellbeing in older community-dwelling Mexicans.

\section{Method}

\subsection{Design and Participants}

A quasi-experimental pilot study was carried out in a convenience sample of 27 adults over 60 to 69 years of age in Mexico City without chronic uncontrolled non-communicable diseases such as type 2 diabetes mellitus, arterial hypertension, Parkinson's disease, psychiatric disorders, epilepsy (or stroke), depression (score $\geq 5$ on the abbreviated Scale of Depression Geriatric Yesavage) [13] or cognitive impairment ( $\leq 20$ in the Montreal Cognitive Assessment) [14]. All participants signed the informed consent. The project was approved by the Ethics Committee of the Universidad NacionalAutónoma de México (UNAM), Zaragoza Campus (Project PAPIME PE305516).

An open invitation was held in Mexico City and 62 people responded, of which 35 met the inclusion criteria and agreed to participate in the investigation. In this sense, 20 subjects accepted to participate in the MSP 20 program (EG, experimental group), of which 4 did not conclude with the program, and 15 subjects were included in the control group (CG) because they did not have time to participate in the MSP, although they agreed to be evaluated at the beginning and after ten weeks, only 11 subjects participated in the second evaluation (Figure 1). For this reason, the data analysis was carried out in the following groups: (i) experimental group (EG) $n=16: 2$ men and 14 women, age $64.3 \pm 3.4$ years, schooling $8.9 \pm 2.6$ years; (ii) control group (CG) $n=11: 3$ men and 8 women, age $64.3 \pm 3.2$, schooling $9.1 \pm 3.3$ years. 


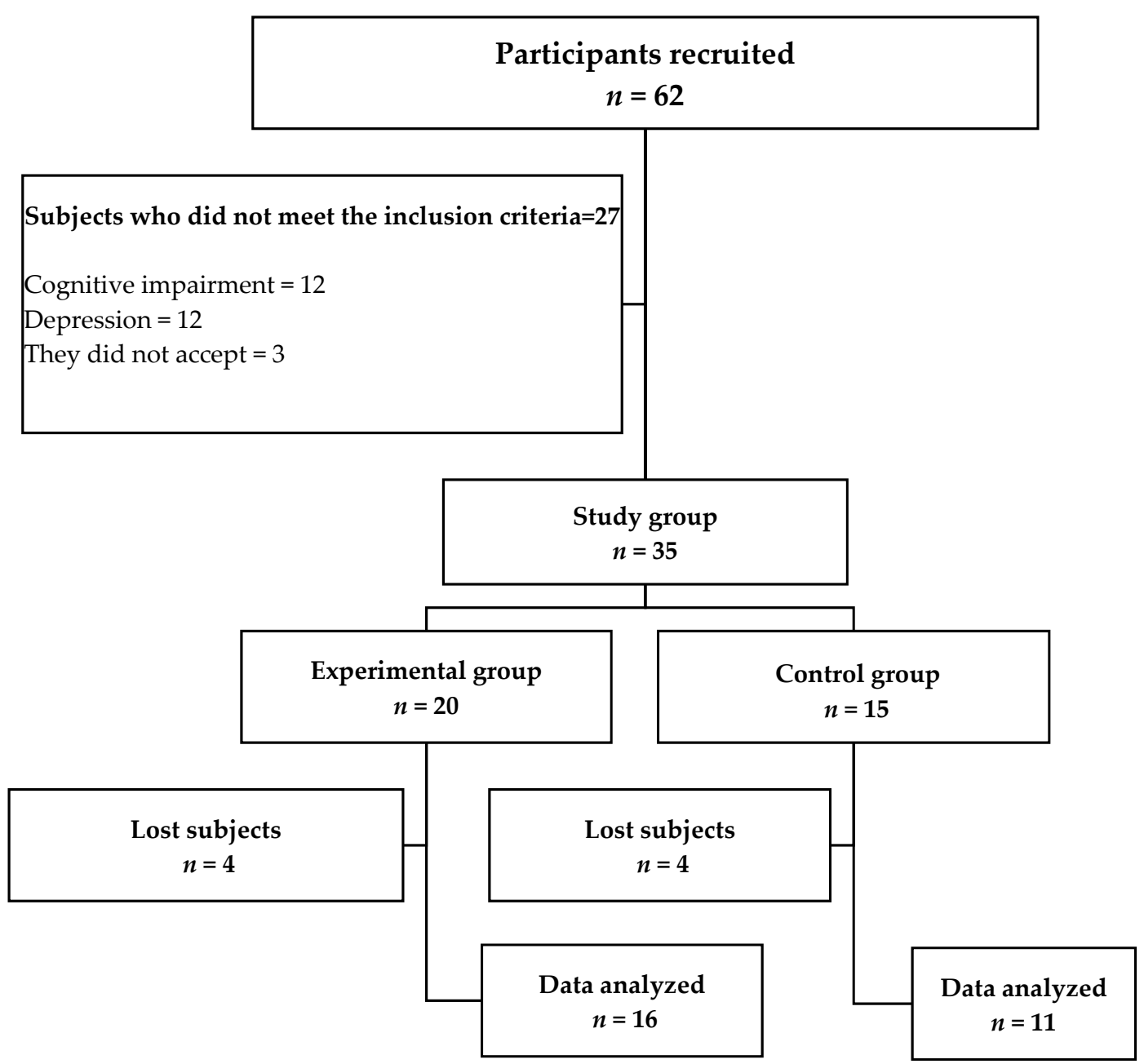

Figure 1. Outline of the study.

\subsection{Intervention}

The MSP consisted of a 40-hour workshop, distributed in 20 sessions, two times a week (ten weeks). The workshop was taught in groups of 10 participants. The instructor wasthe principal investigator. The themes are shown in Table 1, although they were individually adapted according to the interests of the participants.

Table 1. Topics of the computer course.

\begin{tabular}{cc}
\hline 1. Basic conceptsaboutcomputing & 11. Searchfor places onthe Internet \\
\hline 2. Operatingsystem and mouse & 12. Visits to virtual museums \\
3. Keyboard use & 13. Searchforinformationpagesonthe Internet \\
4. Folders and subfolders & 14. Internet procedures \\
5. Folders and subfolders 2 & 15. Downloadmusicfromthe internet \\
6. Basic concepts and Internet search & 16. Search of activitiesfortheweekend \\
7. Searchonthe Internet: images & 17. Searchforentertainment 1 \\
8. Characteristics of Internet pages & 18. Searchforentertainment 2 \\
9. Internet search: videos & 19. Searchforentertainment 3 \\
10. Internet search: Games & 20. Searchforentertainment 4 \\
\hline
\end{tabular}

To encourage the increase of cognitive functions in the implementation of the MSP, the following strategies were incorporated: i) the use of the computer constantly; ii) teach something new in each session, either in procedures or information; iii) that will explore how to perform the activities 
(self-initiated processing) and iv) adjust the difficulty of the task at a high level. Based on the theory of self-determination [5], to improve the subjective wellbeing during the program i) the value of the task was recognized by itself and extrinsic motivation was avoided, for example giving rewards or punishmentsii) positive comments were expressed focusing on the skills of the participants, showing emphasis on the process of doing the activity rather than on the finality, as well as avoiding making destructive criticisms or devalorizing comments to the participants; iii) they were encouraged to choose goals, preferably based on small tasks, feedback was given suggesting elements that would allow them to identify their skills and limits, given the necessary time to answer questions and carry out activities, help was promoted between the participants of the group and suggestions were given to find the information that interested them.

\subsection{Instruments}

All participants were measured before and after the intervention program in processing speed (PS), cognitive inhibition (CI), working and episodicmemory (WM and WE), visuospatial processing (VP), life satisfaction (LS) and positive and negative emotions (PE and NE). The evaluation was carried out by two psychologists, who received a training of 10 hours, in which theoretical and technical aspects of the application and qualification of the instruments were discussed.In addition, each evaluator made two supervised applications to different people of the research participants. The application was made two weeks before and two weeks after the intervention. It has been made individually in two sessions of one hour. The instruments were applied face to face with printed documents.

For the evaluation of cognitive processes, the following instruments were used:

- $\quad$ Processing speed: Test Stroop Color [15]; Symbol Digit Modalities Test (SDMT) [16]; Trail Making Test A [17].

- Working memory: Paced Auditory Serial Addition Test (PASAT) three sec [17]; Trail Making Test B [17]; Letter-Number Sequencing of the WAIS-IV (LNS) [16].

- Cognitive inhibition: Stroop color-word test [15].

- Episodic memory: trial 5, 7 and learnining (sum of trial one to five) of the Rey auditory verbal learning test [18].

- Visuospatial processing: Matrix reasoning of the WAIS-IV [16].

Wellbeing was assessed using the life satisfaction scale $(\alpha=0.83)$ [19] and the Positive and Negative Affect Schedule, positive emotions $(\alpha=0.85-0.90)$ and negative emotions $(\alpha=0.81-0.85)$ [20].

\subsection{Data Analysis}

For the analysis of the data, the SPSS program, version 20, was used. The means and percentages are reported according to the variables evaluated. The pretest score was subtracted from the posttest of each participant, the means and standard deviations of that difference were obtained for each group. We used repeated measures ANOVA to evaluate changes in outcome variables throughout the intervention period considering statistical significance when $p<0.05$; effect size was estimated with the eta cuadradoparcial $\left(\eta_{\mathrm{p}}{ }^{2}\right)$.

\section{Results}

\subsection{Processing Speed}

The EG showed an increase in processing speed in comparison with the CG. However, when performing the ANOVA of repeated measures no statistically significant differences were found between the groups in the scores of the Symbol Digit Modalities Test $F(1,25)=2.1, p=0.15$, $\eta_{\mathrm{p}}{ }^{2}=0.08$, Trail Making Test $\mathrm{A} F(1,25)=3.3, p=0.07, \eta_{\mathrm{p}}{ }^{2}=0.12$; and Stroop Color $F(1,25)=0.22$, $p=0.63, \eta_{\mathrm{p}}^{2}=0.009$ (Table 2). 
Table 2. Mean Score of Processing Speed, Working Memory and Inhibition Tests by Study.

\begin{tabular}{|c|c|c|c|c|c|c|}
\hline & \multicolumn{2}{|c|}{$\begin{array}{l}\text { Experimental Group (EG) } \\
\qquad(n=16)\end{array}$} & \multicolumn{2}{|c|}{$\begin{array}{l}\text { Control Group (CG) } \\
(n=11)\end{array}$} & \multirow[t]{2}{*}{ Change EG } & \multirow[t]{2}{*}{ Change EC } \\
\hline & Pre & Post & Pre & Post & & \\
\hline \multicolumn{7}{|c|}{ Processingspeed } \\
\hline SDMT & $22 \pm 6$ & $25 \pm 7$ & $20 \pm 4$ & $21 \pm 5$ & $3.3 \pm 3.4$ & $0.4 \pm 2.3$ \\
\hline TMTA & $245 \pm 19$ & $256 \pm 14$ & $239 \pm 19$ & $236 \pm 25$ & $11.1 \pm 13.1$ & $-3.3 \pm 13.7$ \\
\hline SC & $58 \pm 6$ & $60 \pm 7$ & $62 \pm 6$ & $58 \pm 1$ & $2.5 \pm 5.3$ & $-4.1 \pm 5$ \\
\hline \multicolumn{7}{|c|}{ Workingmemory } \\
\hline ТМТВ & $161 \pm 51$ & $181 \pm 45$ & $151 \pm 41$ & $147 \pm 47$ & $24.0 \pm 6$ & $19.2 \pm 5.8$ \\
\hline LNS & $13 \pm 2$ & $14 \pm .2$ & $13 \pm 3$ & $12 \pm 3$ & $1.4 \pm 1.7$ & $-1.1 \pm 1.7$ \\
\hline PASAT 3s & $30.7 \pm 7$ & $33.4 \pm 10.4$ & $29.1 \pm 7.4$ & $27.0 \pm 9.4$ & $2.7 \pm 6.1$ & $-2.1 \pm 4.9$ \\
\hline \multicolumn{7}{|c|}{ Cognitive inhibition } \\
\hline SC-W & $29 \pm 6$ & $32 \pm 7$ & $30 \pm 6$ & $30 \pm 6$ & $3.2 \pm 3.3$ & $-0.6 \pm 5.0$ \\
\hline
\end{tabular}

Repeated measures ANOVA $p<0.05$, PS: Processing speed; WM: Working memory; SDMT: Symbol Digit Modalities Test; TMT A: Trail Making Test A; SC: Stroop color; TMT B: Trail Making Test B; LNS: Letter-Number Sequencing; PASAT: Paced Auditory Serial Addition Test; SC-W:Stroop color-Word

\subsection{Working Memory and Cognitive Inhibition}

There was an increase in the score in the tests of working memory and cognitive inhibition in the EG, nevertheless, when performing the ANOVA test of repeated measures no statistically significant differences were observed between the groups in the scores of the Trail Making Test B $F(1,25)=1.5$, $p=0.22, \eta_{\mathrm{p}}^{2}=0.05$; Letter-Number Sequencing $F(1,25)=1.2, p=0.28, \eta_{\mathrm{p}}{ }^{2}=0.04$; Paced Auditory Serial Addition Test $F(1,25)=1.4, p=0.23, \eta_{\mathrm{p}}{ }^{2}=0.05$; and Stroop color-Word $F(1,25)=0.1, p=0.74$, $\eta_{\mathrm{p}}^{2}=0.004$ (Table 2).

\subsection{Episodic Memory}

A statistically significant increase in the test score was observed to measure the episodic memory in the EG compared to the CG. With the ANOVA analysis of repeated measurements was observed effect of the MSP the trial $5 F(1,25)=6.6, p=0.01, \eta_{p}^{2}=0.21$; and learning $F(1,25)=11.8, p=0.002$, $\eta_{\mathrm{p}}{ }^{2}=0.32$. (Table 3).

Table 3. Mean Score of Episodic Memory and Visuospatial Processing Tests by Study Group.

\begin{tabular}{|c|c|c|c|c|c|c|}
\hline & \multicolumn{2}{|c|}{$\begin{array}{l}\text { Experimental Group (EG) } \\
\qquad(n=16)\end{array}$} & \multicolumn{2}{|c|}{$\begin{array}{c}\text { Control Group (CG) } \\
(n=11)\end{array}$} & \multirow[t]{2}{*}{ Change EG } & \multirow[t]{2}{*}{ Change CG } \\
\hline & Pre & Post & Pre & Post & & \\
\hline \multicolumn{7}{|c|}{ Episodicmemory } \\
\hline E5 & $11 \pm 2$ & $13 \pm 1$ & $11 \pm 2$ & $10 \pm 2$ & $2.3 \pm 1.8^{*}$ & $-0.3 \pm 1.6$ \\
\hline Learning & $41 \pm 6$ & $53 \pm 6$ & $40 \pm 5$ & $41 \pm 7$ & $12.2 \pm 7.2^{*}$ & $0.73 \pm 5.5$ \\
\hline E7 & $10 \pm 2$ & $11.0 \pm 1.7$ & $9.2 \pm 1.6$ & $10 \pm 2$ & $1.2 \pm 2.3$ & $0.4 \pm 2.3$ \\
\hline \multicolumn{7}{|c|}{ Visuospatial processing } \\
\hline MR & $9 \pm 4$ & $12 \pm 4$ & $8 \pm 2$ & $8 \pm 3$ & $2.9 \pm .7^{*}$ & $1.1 \pm 0.03$ \\
\hline
\end{tabular}

\subsection{Visuospatial Processing}

A positive effect on visuospatial processing was observed in the EG group compared to the CG group. When performing the repeated measures ANOVA test, a statistically significant increase was found in the evaluation of the Matrix Reasoning test $F(1,25)=5.2, p=0.03, \eta_{p}{ }^{2}=0.17$ (Table 3). 


\subsection{Subjective Wellbeing}

No statistically significant differences were observed between the EG and CG in the scores of negative emotion test, $F(1,25)=0.75, p=0.72, \eta_{\mathrm{p}}{ }^{2}=0.004$; positive emotion test, $F(1,25)=0.26, p=0.61$, $\eta_{\mathrm{p}}^{2}=0.01$; and satisfaction with life test, $F(1,25)=3.7, p=0.06, \eta_{\mathrm{p}}^{2}=0.12$ (Table 4 ).

Table 4. Mean Score of Negative and Positive Emotion and Satisfaction with Life Tests by Study Group.

\begin{tabular}{|c|c|c|c|c|c|c|}
\hline & \multicolumn{2}{|c|}{$\begin{array}{l}\text { Experimental Group (EG) } \\
\qquad(n=16)\end{array}$} & \multicolumn{2}{|c|}{$\begin{array}{l}\text { Control Group (CG) } \\
\qquad(n=11)\end{array}$} & \multirow[t]{2}{*}{ Change EG } & \multirow[t]{2}{*}{ ChangeCG } \\
\hline & Pre & Post & Pre & Post & & \\
\hline $\mathrm{NE}$ & $22.19 \pm 8.2$ & $16.7 \pm 5.6$ & $22.82 \pm 5.6$ & $17.5 \pm 6.9$ & $-5.5 \pm 6.7$ & $-5.2 \pm 4.7$ \\
\hline PE & $37.1 \pm 7.0$ & $41.4 \pm 6.5$ & $39.09 \pm 5.7$ & $37.1 \pm 5.5$ & $4.2 \pm 5.2$ & $-1.9 \pm 4.8$ \\
\hline SL & $19.63 \pm 2.3$ & $21.4 \pm 1.7$ & $18.5 \pm 1.9$ & $19.7 \pm 2.5$ & $1.7 \pm 2.2$ & $1.2 \pm 2.2$ \\
\hline
\end{tabular}

Repeated measures ANOVA $p>0.05$, NE: Negative emotion; PE, Positive emotion; SL; Satisfaction with Life.

\section{Discussion}

Human aging is a gradual and adaptive process, characterized by a relative decrease in the biological and cognitive reserve and response to demands to maintain or restore homeostasis, due to morphological, physiological, biochemical, psychological, and social changes, prompted by genetic load and accumulated wear, and the challenges that a person faces throughout their life in a given environment [21]. In this sense, cognitive aging is a complex process in which there is an increase in the accumulation of knowledge and, in turn, a decrease in the capacity to process new information. In addition, processes related to attention such as processing speed, working memory and cognitive inhibition begin to descend from the age of 30 , with a lower variability between individuals, instead, cognitive processes related to memory and reasoning begin to descend to 60 years, with greater variability between individuals $[22,23]$.

Knowledge about strategies that can avoid or defer the decline in cognitive functions with aging, mainly those related to care is not conclusive [24]. However, it has been shown that mental stimulation could be a practical and accessible strategy to maintain cognitive functions and that the person continues with their autonomy and independence throughout the life cycle up to old age [25].

In the present study we tried a program of mental stimulation of learning of the use of Internet and the computer, in which we found a positive effect on the episodic memory and the visuospatial processing. The foregoing contrasts with the findings ofSlegers et al. (2009), that the use of the computer does not have an impact on cognitive functions [9]. These differences may be due to the fact that we included specific strategies to maintain the cognitive functions that have been implemented in other mental stimulation interventions $[11,12,26,27]$. This suggests that to achieve an impact on cognitive functions, not only must a task be performed that is considered intellectually stimulating, but the task has to encourage the use of cognitive processes, self-initiated processing, learning and an adjustment of tasks for a high cognitive effort.

Our results can be explained by considering the scaffolding theory of aging and cognition [28] and adult cognitive plasticity theory [4]. The scaffolding is the recruitment of additional neural networks that support the declining structures whose functioning became noisy, inefficient or both. This is formed by learning something new and activities related to executive functions. The area of the brain in which it develops is mainly the frontal lobe [23]. They can also be explained by the plasticity of the brain, which allows the development of anatomical changes. Plasticity is generated by keeping the demands of the environment high for the individual, in such a way that it can acquire more processing resources or knowledge to adapt to the environment, generating new connections in the brain [4].

We found a positive change in episodic memory and visuospatial processing in the EG; however, no statistically significant differences were observed in the variables related to attention such as working memory, processing speed and cognitive inhibition between the groups (EG and CG). These findings 
are consistent with what has been reported in other studies, which showed that learning to use a tablet or digital photograph had a positive effect on episodic memory, butnot in attention [11,26].

On the other hand, it has been shown that performing different stimulating activities in supervised programs such as learning computer skills, practicing theater and helping children with their homework has a positive effect on cognitive functions [1]. This supports the proposal that mental stimulation can improve or maintain cognitive functions, considering thedesign of programs with activities that respond to the interest of the population and ensure engagement, adherence and a growing effort [21].

It has been proposed that mental stimulation can improve subjective wellbeing [26]. We design the intervention based on the theory of self-determination to promote wellbeing through positive comments and a structure of activity that promotes autonomy, competence and relatedness.

After the intervention, we found that the participants of the mental stimulation group did not show statistically significant changes in the scores of Processing Speed, Working Memory and Inhibition tests, and the subjective wellbeing tests. In this sense, it is important to note that the control group self-selected, because they did not agree to participate, because they did not have time. Therefore, their daily activities could have influenced the results, especially if the activities were stimulating, complex and satisfactory, these could influence the cognitive functions and subjective wellbeing. In this regard, it has been pointed out that the types and characteristics of activities that promote subjective wellbeing and cognitive health should be identified, since the resources generated will motivate people to continue with these activities and, in turn, these resources will allow healthier behaviors [29].

Finally, it is important to point out that the present study has some limitations, such as a small sample size, the lack of random assignment of the groups, and the lack of monitoring of the activities that could influence cognitive functions and subjective wellbeing in the control group. In this regard, we suggest continuing with this line of research considering a representative sample size, random assignment of the groups and include in the design the registration and measurement of the activities carried out by the participants in the control group that could influencethe cognitive functions and subjective wellbeing.

\section{Conclusions}

Our findings suggest that mental stimulation based on the learning of computer and Internet use, have a positive effect episodic memory and visuospatial processing. Thus, this study supports the proposal to recommend the mental stimulation as an alternative to maintain or improve the cognitive functions of older adults.

Author Contributions: J.M.S.-N. and V.M.M.-N. designed the study, wrote the manuscript and analyzed the data. M.L.M.-M. and M.M.-L.L. analyzed the data. All authors reviewed the final manuscript.

Funding: This research received no external funding.

Acknowledgments: This project was supported by a grant from the Secretaría de Educación, Ciencia, Tecnología e Innovación de la Ciudad de México SECITI/042/2018 “Red colaborativa de InvestigaciónTraslacionalpara el EnvejecimientoSaludable de la Ciudad de México (RECITES)". Programa de Maestría y Doctorado en Psicología, Universidad Nacional Autónoma de México.ConsejoNacional de Ciencia y Tecnología (Beca de Posgrado CONACYT CVU 411025).

Conflicts of Interest: The authors declare no conflicts of interest.

\section{References}

1. Kelly, M.E.; Loughrey, D.; Lawlor, B.A.; Robertson, I.H.; Walsh, C.; Brennan, S. The impact of cognitive training and mental stimulation on cognitive and everyday functioning of healthy older adults: A systematic review and meta-analysis. Ageing Res. Rev. 2014, 15, 28-43. [CrossRef] [PubMed]

2. Diener, E.; Napa Scollon, C.; Lucas, R.E. The evolving concept of subjective well-being: The multifaceted nature of happiness. In Assessing Well-Being: The Collected Works of Ed Diener; Diener, E., Ed.; Springer: New York, NY, USA, 2009; pp. 67-100.

3. Park, D.C.; Gutchess, A.H.; Meade, M.L.; Stine-Morrow, E.A.L. Improving cognitive function in older adults: Nontraditional approaches. J. Gerontol. B Psychol. Sci. Soc. Sci. 2007, 62, 45-52. [CrossRef] [PubMed] 
4. Lovden, M.; Backman, L.; Lindenberger, U.; Schaefer, S.; Schmiedek, F. A Theoretical framework for the study of adult cognitive plasticity. Psychol. Bull. 2010, 136, 659-676. [CrossRef] [PubMed]

5. Deci, E.L.; Ryan, R.M. Self-determination theory: A macrotheory of human motivation, development, and health. Can. Psychol. 2008, 49, 182-185. [CrossRef]

6. Gatto, S.L.; Tak, S.H. Computer, Internet, and E-mail Use among older adults: Benefits and barriers. Educ. Gerontol. 2008, 34, 800-811. [CrossRef]

7. Small, G.W.; Moody, T.D.; Siddarth, P.; Bookheimer, S.Y. Your brain on Google: patterns of cerebral activation during Internet searching. Am. J. Geriatr. Psychiatry 2009, 17, 116-126. [CrossRef]

8. Klimova, B.; Maresova, P. Computer-Based Training programs for older people with mild cognitive impairment and/or dementia. Front. Hum. Neurosci. 2017, 11, 262. [CrossRef] [PubMed]

9. Slegers, K.; van Boxtel, M.; Jolles, J. Effects of computer training and internet usage on cognitive abilities in older adults: A randomized controlled study. Aging Clin. Exp. Res. 2009, 21, 43-54. [CrossRef]

10. Klusmann, V.; Evers, A.; Schwarzer, R.; Schlattmann, P.; Reischies, F.M.; Heuser, I.; Dimeo, F.C. Complex mental and physical activity in older women and cognitive performance: A 6-month randomized controlled trial. J. Gerontol. A Biol. Sci. Med. Sci. 2010, 65, 680-688. [CrossRef]

11. Chan, M.Y.; Haber, S.; Drew, L.M.; Park, D.C.; Haber, S.; Drew, M. Training older adults to use tablet computers: Does it enhance cognitive function? Gerontologist. 2016, 56, 475-484. [CrossRef]

12. Vaportzis, E.; Martin, M.; Gow, A.J. A Tablet for healthy ageing: The effect of a Tablet computer training intervention on cognitive abilities in older adults. Am. J. Geriatr. Psychiatry. 2016, 25, 841-851. [CrossRef] [PubMed]

13. Martínez, J.; Onís, M.C.; Dueñas, R.; Albert, C.; Aguado, C.; Luque, R. Versiónespañola del cuestionario de Yesavageabreviado (GDS)para eldespistaje de depresión en mayores de 65 años: Adaptacióny validación. Medifam. 2002, 12, 620-630.

14. Pedraza, O.L.; Salazar, A.M.; Sierra, F.A.; Soler, D.; Castro, J.; Castillo, P.; Hernández, A.; Piñeros, C.; Bogotá, D.C. Confiabilidad, validez de criterio y discriminantedel Montreal Cognitive Assessment (MoCA) test, en un grupo de adultos de Bogotá. Acta Médica Colomb. 2016, 41, 221-228.

15. Artiola, F.L.; Hermosillo, R.D.; Heaton, R.K. Manual de normas y procedimientospara la bateríaneuropsicológicaenespañol; M Press: Tucson, AZ, USA, 1999.

16. Wechsler, D. EscalaWeschsler de inteligenciaparaadultos-IV; Manual Moderno: México, México, 2014.

17. Villa-Rodríguez, M.Á.; Navarro, M.E.C.; Villaseñor, T.J. EvaluaciónNeuropsicológicabásicaparaadultos (ENBA)-ProyectoNeuronorma-Mx. 2018. Available online: http://www.manualmoderno.com/apoyos_ electronicos/9786074485813/ingr_9786074485813.php (accessed on 7 January 2019).

18. Sánchez-Nieto, J.M.; Villa-Rodríguez, M.Á.; Mendoza-Núñez, V.M. Rendimientoen el test de aprendizajeauditivo verbal de Rey enunapoblación de adultosmayores de México. Rev. Mex. Neurocienc. 2016, 17, 37-44.

19. Padrós, F.; Gutiérrez, C.Y.; Medina, M.A. PropiedadesPsicométricas de la escala de satisfacción con la vida (SWLS) de Dienerenpoblación de Michoacán (México). Av. Psicol. Latinoam. 2015, 33, 223-232. [CrossRef]

20. Robles, R.; Páez, F. Estudiosobre la traducción al español y laspropiedadespsicométricas de lasescalas de AfectoPositivo y Negativo (PANAS). Salud Ment. 2003, 26, 69-75.

21. Mendoza-Núñez, V.M.; Vivaldo-Martínez, M.; Martínez-Maldonado, M.L. Community model of health y aging framed in resilience and generativity. Rev. Med. Inst. Mex. Seguro Soc. 2018, 56, 110-119.

22. Salthouse, T.A. When does age-related cognitive decline begin? Neurobiol. Aging. 2012, 100, $130-134$. [CrossRef]

23. Craik, F.I.M.; Bialystok, E. Cognition through the lifespan: Mechanisms of change. Trends Cogn. Sci. 2006, 10, 131-138. [CrossRef]

24. Salthouse, T.A. Mental Exercise and Mental Aging. Evaluating the Validity of the "Use It or Lose It" Hypothesis. Perspect. Psychol. Sci. 2006, 1, 68-87. [CrossRef]

25. Schooler, C. Use Itand Keep It, Longer, Probably. Perspect. Psychol. Sci. 2007, 2, 24-29. [CrossRef] [PubMed]

26. Park, D.C.; Lodi-Smith, J.; Drew, L.; Haber, S.; Hebrank, A.; Bischof, G.N.; et al. The impact of sustained engagement on cognitive function in older adults: The Synapse Project. Psychol. Sci. 2014, 25, 103-112. [CrossRef] [PubMed]

27. Noice, H.; Noice, T. An Arts Intervention for Older Adults Living in Subsidized Retirement Homes. Neuropsychol. Dev. Cogn. B Aging Neuropsychol. Cogn. 2009, 16, 56-79. [CrossRef] [PubMed] 
28. Park, D.C.; Reuter-Lorenz, P. T head adaptive brain: aging and neurocognitive scaffolding. Ann. Rev. Psychol. 2009, 60, 173-196. [CrossRef] [PubMed]

29. Fredrickson, B.L.; Branigan, C. Positive emotions broaden the scope of attention and thought-action repertoires. Cogn. Emot. 2005, 19, 313-332. [CrossRef] [PubMed]

(C) 2019 by the authors. Licensee MDPI, Basel, Switzerland. This article is an open access article distributed under the terms and conditions of the Creative Commons Attribution (CC BY) license (http://creativecommons.org/licenses/by/4.0/). 